\title{
SISTEM INFORMASI GEOGRAFIS LOKASI KOS DAN PENGINAPAN BERBASIS WEB PADA WILAYAH KOTABUMI KABUPATEN LAMPUNG UTARA
}

\author{
Dwi Marissa Efendi ${ }^{1}$, Joni Darsyah ${ }^{2}$ \\ Program Studi Sistem Informasi ${ }^{1}$,Jurusan Sistem Informasi ${ }^{2}$ \\ STMIK Dian Cipta Cendikia Kotabumi \\ Jl.Negara No.03 Candimas, Lampung Utara \\ Dwi.marisa@dcc.ac.id ${ }^{1}$, jonnydarsyah@gmail.com ${ }^{2}$
}

\begin{abstract}
ABSTRAK
Sistem informasi tempat kos berguna sebagai penyedia informasi yang lengkap mengenai tempat kos, mahasiswa tidak perlu menghabiskan waktu untuk mendatangi tempat kos satu persatu demi mencari informasi mengenai tempat kos. Dengan adanya Sistem Jasa Pencarian Kos ini sangat bermanfaat bagi keefektifan dan keefisienan waktu. Ketersediaan informasi mengenai rumah kos yang bisa memberikan gambaran bagi pencari kos seperti fasilitas, ketersediaan kamar, informasi biaya sewa, dan lokasi rumah kos, dan peta untuk menunjukan lokasi rumah kos.
\end{abstract}

Dalam penelitian ini menggunakan jenis penelitian Extreme Programming. Extreme Programming (XP) merupakan suatu pendekatan yang paling banyak digunakan untuk pengembangan perangkat lunak cepat. Alasan menggunakan metode Extreme Programming (XP) karena sifat dari aplikasi yang di kembangkan dengan cepat melalui tahapan - tahapan yang ada meliputi : Planning / Perencanaan, Design/ Perancangan, Coding/Pengkodean dan Testing/Pengujian.

Dengan adanya sistem ini dapat memudahkan pengguna dalam pencarian lokasi lokasi kos dan penginapan di wilayah Lampung Utara.

Kata kunci : Sistem Informasi, SIG_Kosan, Extreme Programming. 


\begin{abstract}
Information system for boarding houses is useful as a provider of complete information about boarding houses, students do not need to spend time to visit the boarding place one by one in search of information about boarding houses. With this Kos Search Service System, it is very useful for the effectiveness and efficiency of time. Availability of information about boarding houses that can provide an overview for boarders such as facilities, room availability, rental fee information, and boarding house locations, and maps to show the location of boarding houses.

In this study the authors used the type of Extreme Programming research. Extreme Programming (XP) is the most widely used approach to fast software development. Reasons for using the Extreme Programming (XP) method because of the nature of the application that is developed quickly through the existing stages include: Planning / Planning, Design / Design, Coding / Coding and Testing / Testing.
\end{abstract}

With this system, it is easier for users to search locations for boarding houses and lodging in the North Lampung region.

Keywords: Information Systems, SIG_Kosan, Extreme Programming 


\section{PENDAHULUAN}

Perkembangan teknologi berperan penting bagi kehidupan manusia terutama bidang teknologi informasi seperti internet. Sistem informasi geografis merupakan salah satu perkembangan dari teknologi informasi.

Sistem adalah komponen atau bagian yang saling berkaitan yang sama sama berfungsi untuk mencapai suatu tujuan, misalnya computer yang terdiri dari beberapa sistem yaitu perangkat kera $\mathrm{s}$ (Hardware ), perangkat lunak ( Software ) dan perangkat manusi (Brainware ) yang masing - masing saling berintegrasi sehingga tercapai suatu tujuan yang ingin dicapai. [1]

Sistem Informasi Geografis (SIG) atau juga dikenal sebagai Geographic Information System (GIS) merupakan sistem informasi berbasis komputer yang menggabungkan antara unsur peta (geografis) dan informasinya tentang peta tersebut (data atribut). Sistem Informasi Geografis (SIG) dirancang untuk mendapatkan, mengelola, memanipulasi, analisa, memperagakan dan menampilkan data spesial (keruangan) secara detail dan akurat terhadap lokasilokasi yang ingin dicari letak keberadaannya. [4]

Sistem informasi tempat kost berguna sebagai penyedia informasi yang lengkap mengenai tempat kost, mahasiswa tidak perlu menghabiskan waktu untuk mendatangi tempat kost satu persatu demi mencari informasi mengenai tempat kost. Dengan adanya Sistem Jasa Pencarian Kost ini sangat bermanfaat bagi keefektifan dan keefisienan waktu. Ketersediaan informasi mengenai rumah kost yang bisa memberikan gambaran bagi pencari kost seperti fasilitas, ketersediaan kamar, informasi biaya sewa, dan lokasi rumah kost, dan peta untuk menunjukan lokasi rumah kost.

Berdasarkan latar belakang diatas maka peneliti mengangkat judul "Sistem Informasi Geografi Lokasi Kos Dan Penginapan Berbasis Web Pada Wilayah Kotabumi Kabupaten Lampung Utara"

\section{METODOLOGI PENELITIAN}

\subsection{Metode Pengembangan Sistem}

Adapun tahapan pada

Extreme Programming dapat di jelaskan sebagai berikut [2]:

\subsubsection{Planning / Perencanaan}

Pada tahap perencanaan ini dimulai dari pengumpulan kebutuhan yang membantu tim teknikal untuk memahami konteks bisnis dari sebuah aplikasi. Selain itu pada tahap ini juga mendefinisikan output yang akan dihasilkan, fitur yang dimiliki oleh aplikasi dan fungsi dari aplikasi yang dikembangkan.[3]

\subsubsection{Design / Perancangan}

Metode ini menekankan desain aplikasi yang sederhana, untuk mendesain aplikasi 
dapat menggunakan Class - Responsibility - Collaborator (CRC) cards yang mengidentifikasi dan mengatur class pada object-oriented.

\subsubsection{Coding / Pengkodean}

Konsep utama dari tahapan pengkodean ada extreme programming adalah pair programming, melibatkan lebih dari satu orang untuk menyusun kode.[5]

\subsubsection{Testing / Pengujian}

Pada tahapan ini lebih fokus pada pengujian fitur dan fungsionalitas dari aplikasi.

\subsection{Alat pengembangan Sistem}

\section{A. Use Case Diagram}

Use case adalah gambaran fungsionalitas dari suatu sistem, sehingga admin atau pengguna sistem paham dan mengerti mengenai kegunaan sistem yang akan dibangun. Berikut adalah use case diagram yang diusulkan :

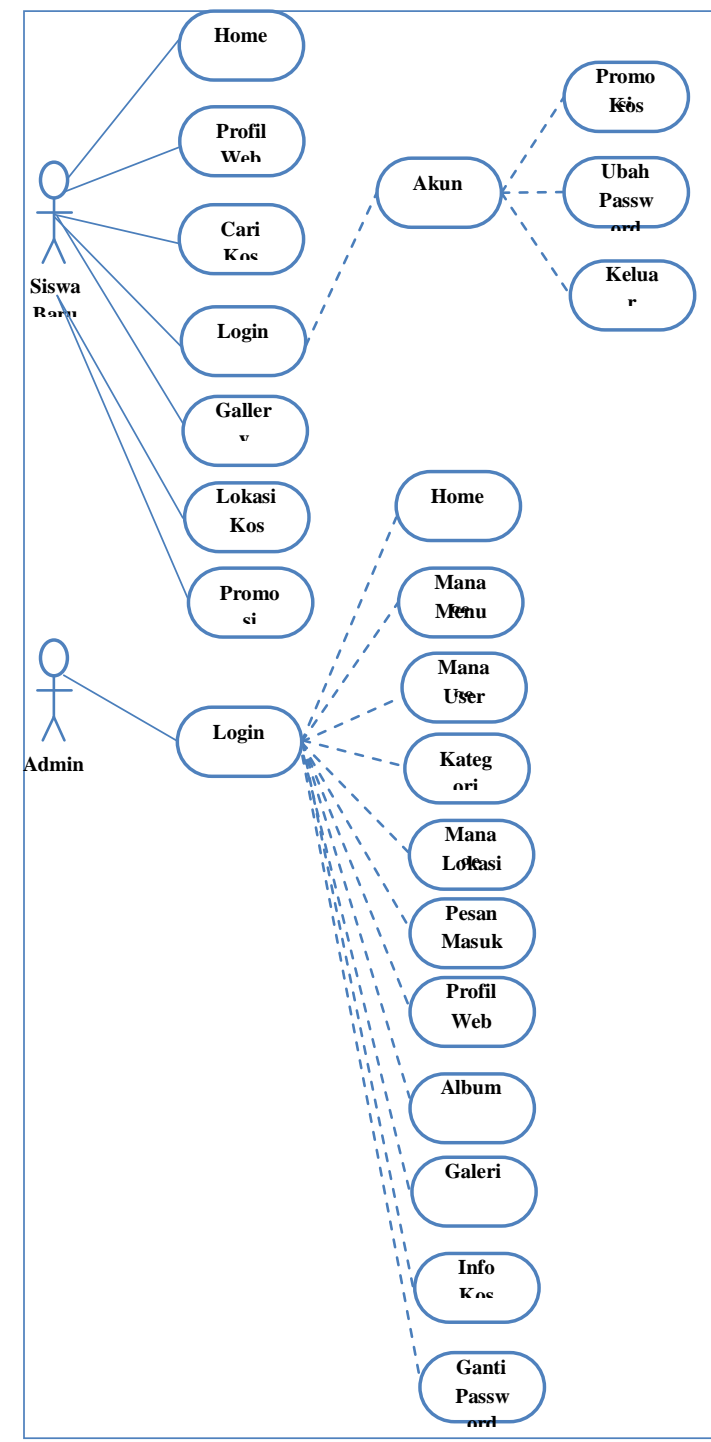

Gambar 1 Use Case Diagram

\section{B. Activity Diagram \\ 1. Activity Diagram Admin Melihat Informasi}




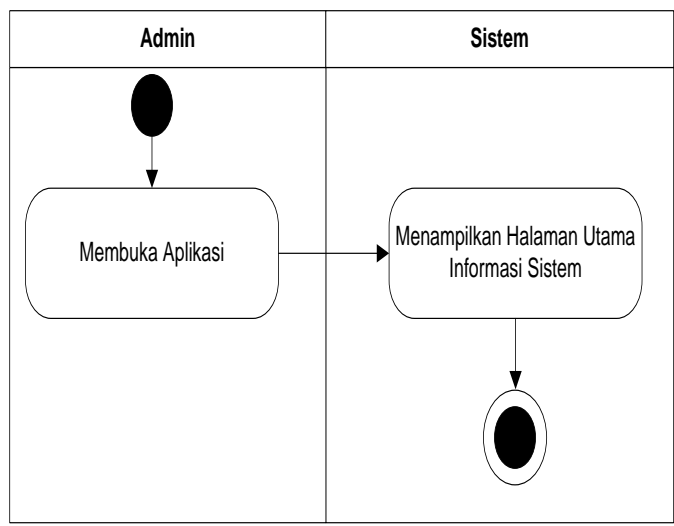

Gambar 2 Activity Diagram Admin Melihat Informasi

\section{Activity Diagram User Melihat} Informasi

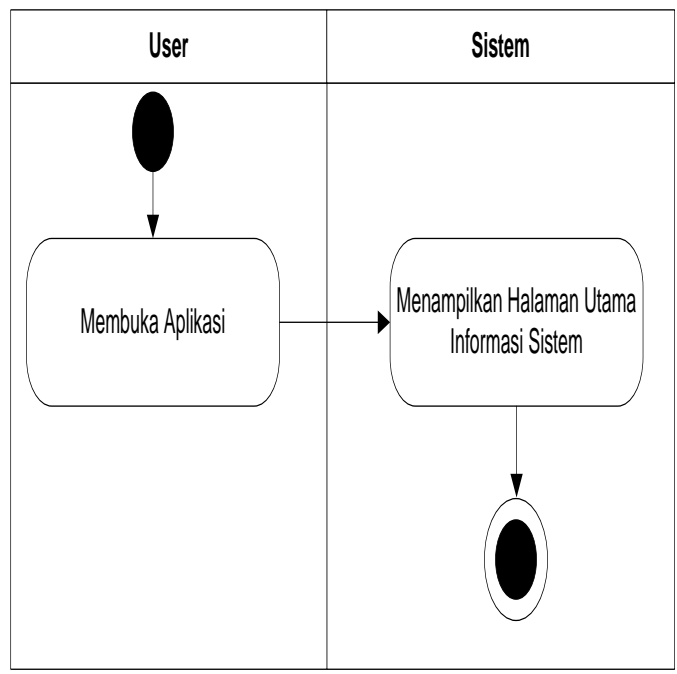

Gambar 3 Activity Diagram User Melihat Informasi

\section{Activity Diagram Search Informasi}

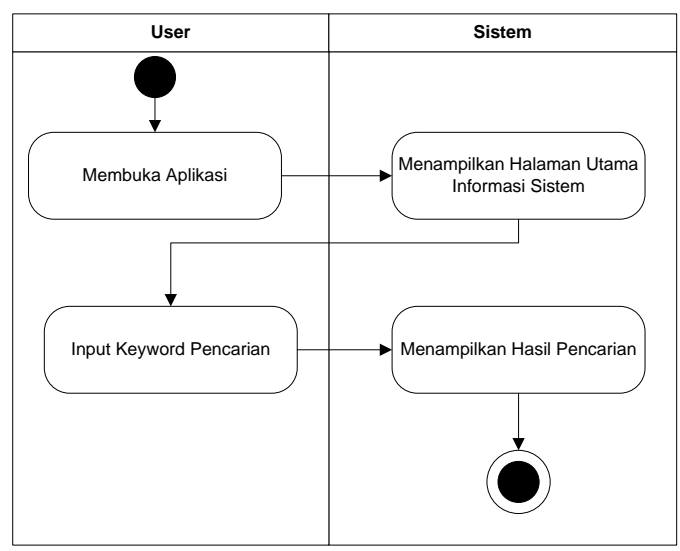

\section{Gambar 4 Activity Diagram Search Informasi}

\section{Activity Diagram Admin Mengubah Data}

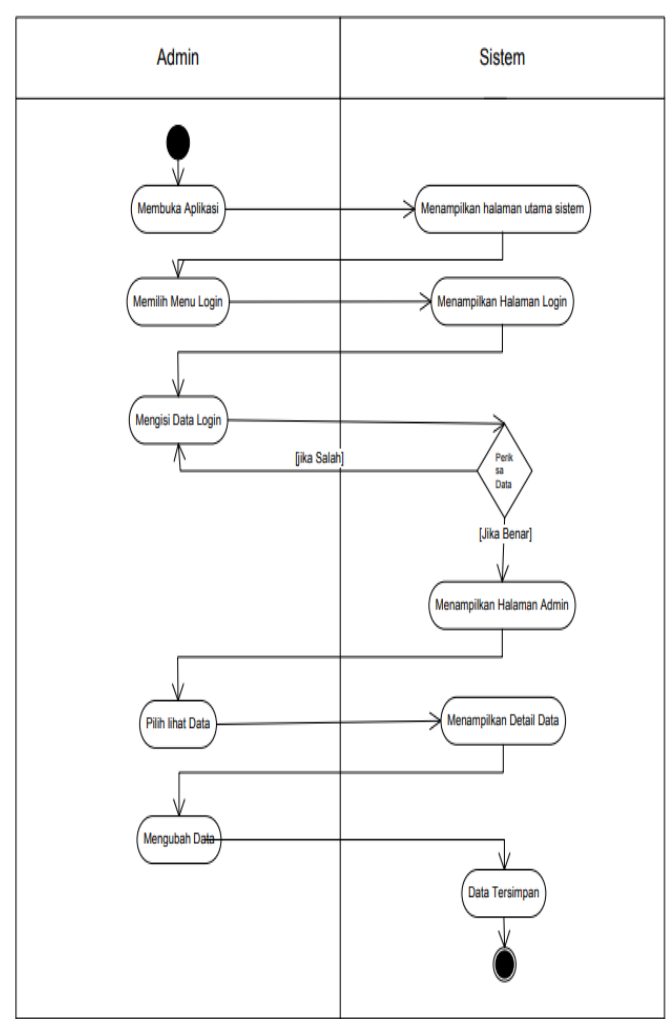

Gambar 5 Activity Diagram Admin

Mengubah Data

\section{Sequence Diagram}

1. Sequence Diagram Proses User Melihat Informasi

Sequence Diagram melihat informasi sistem yang menampilkan halaman peta yang berisi titik-titik lokasi kosan dan penginapan. 


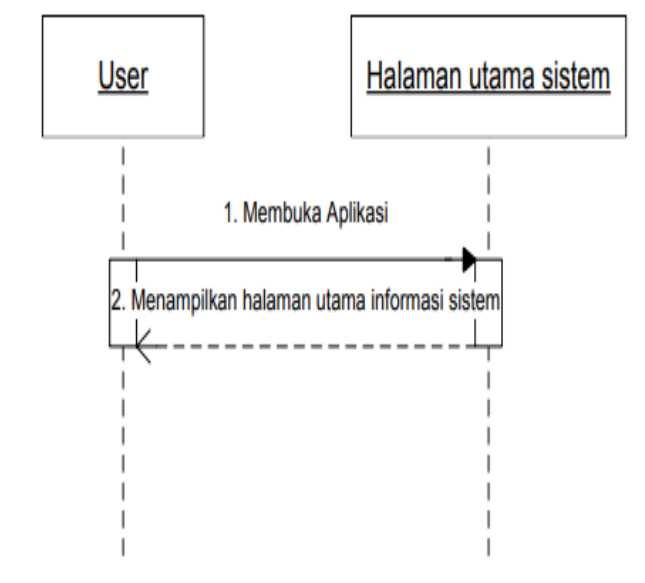

Gambar 6 Sequence Diagram User Melihat Informasi

\section{Sequence Diagram Proses Admin Melihat Informasi}

Sequence Diagram melihat informasi sistem yang menampilkan halaman peta yang berisi titik-titik lokasi kosan dan penginapan.

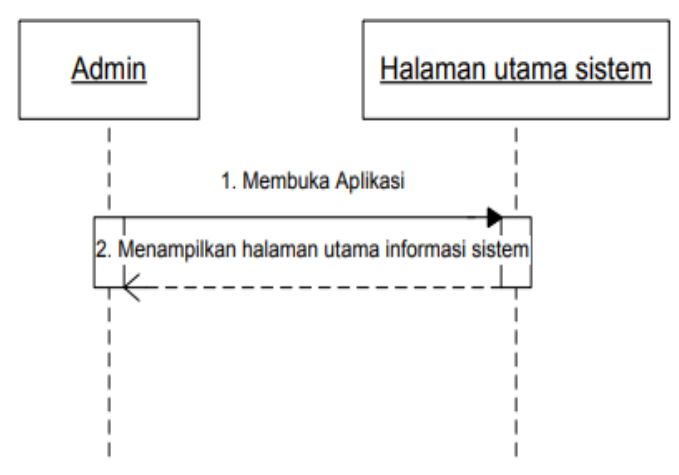

Gambar 7 Sequence Diagram Admin

Melihat Informasi

\section{Sequence Diagram Proses User Search}

Sequence Diagram Proses Search yang digunakan oleh pengguna. Pengguna menggunakan Aplikasi dengan membuka aplikasi, setelah itu akan tampil halaman utama sistem, yang berisi toolbox search dengan memasukkan keyword pencarian, kemudian langsung tampil hasil pencarian di halaman pencarian.

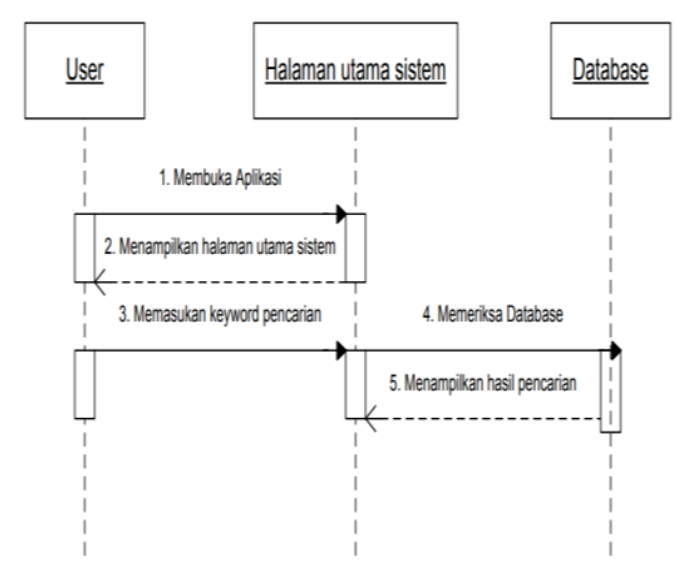

Gambar 8 Sequence Diagram Proses User Search

\section{Sequence Diagram Proses Admin Mengubah Data}

Sequence Diagram Proses Search yang digunakan oleh pengguna. Pengguna menggunakan Aplikasi dengan membuka aplikasi, setelah itu akan tampil halaman utama sistem, yang berisi toolbox search dengan memasukkan keyword pencarian, kemudian langsung tampil hasil pencarian di halaman pencarian. 


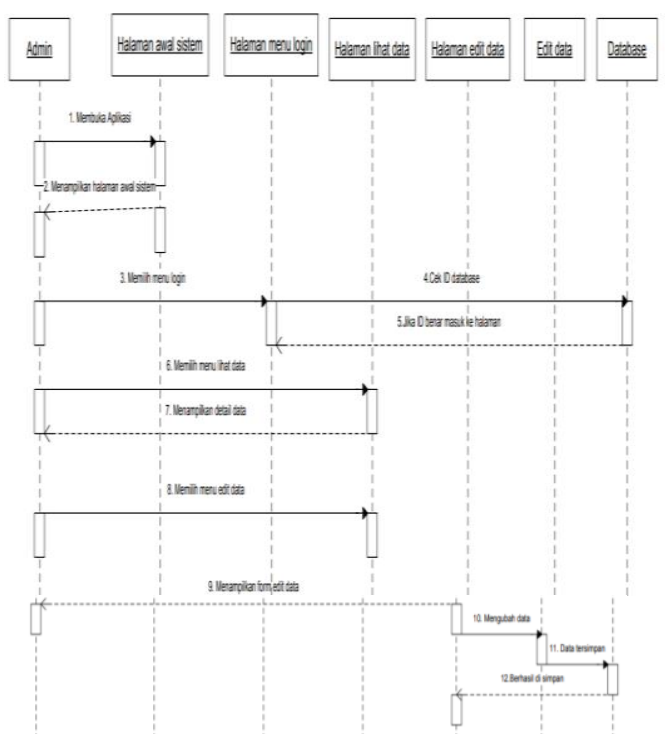

Gambar 9 Sequence Diagram Proses Admin Mengubah Data

\section{HASIL DAN PEMBAHASAN}

\subsection{Hasil Program}

\subsubsection{Tampilan Home}

Pada halaman home, user dapat melihat menu profil web, gallery, lokasi kost, transaksi dan menu login untuk user yang telah registrasi untuk mempromosikan tempat kost atau penginapannya.

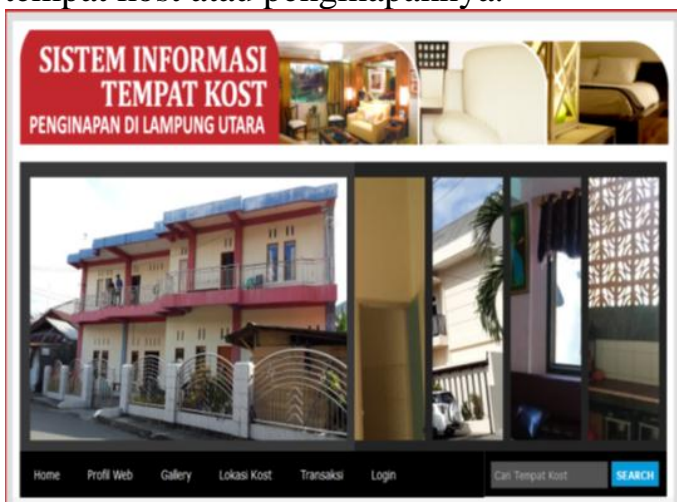

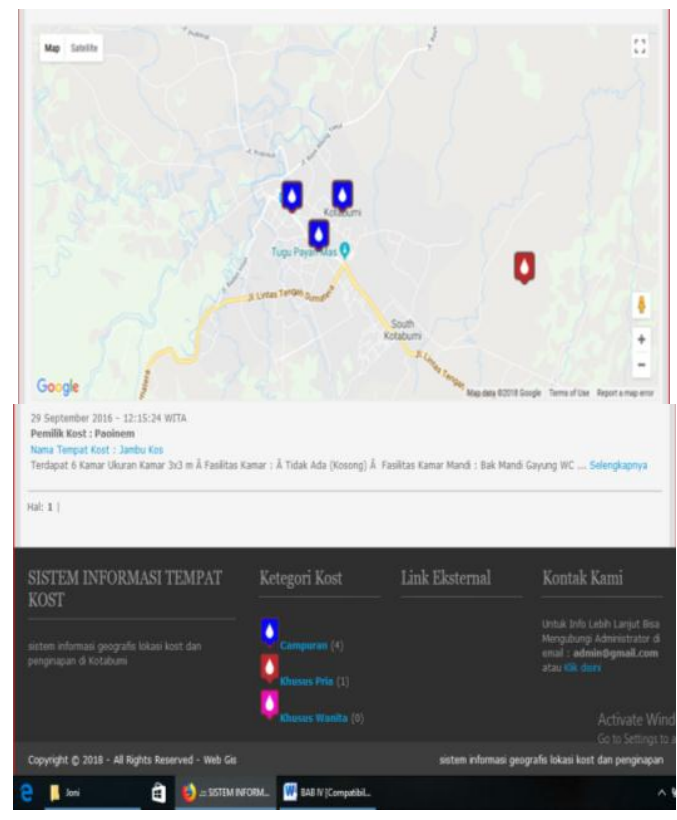

Gambar 10 Tampilan Home

\subsubsection{Tampilan Profil Web}

Pada halaman ini user dapat melihat profil web,kapan dibuat, siapa programmernya dan pemilik web tersebut.

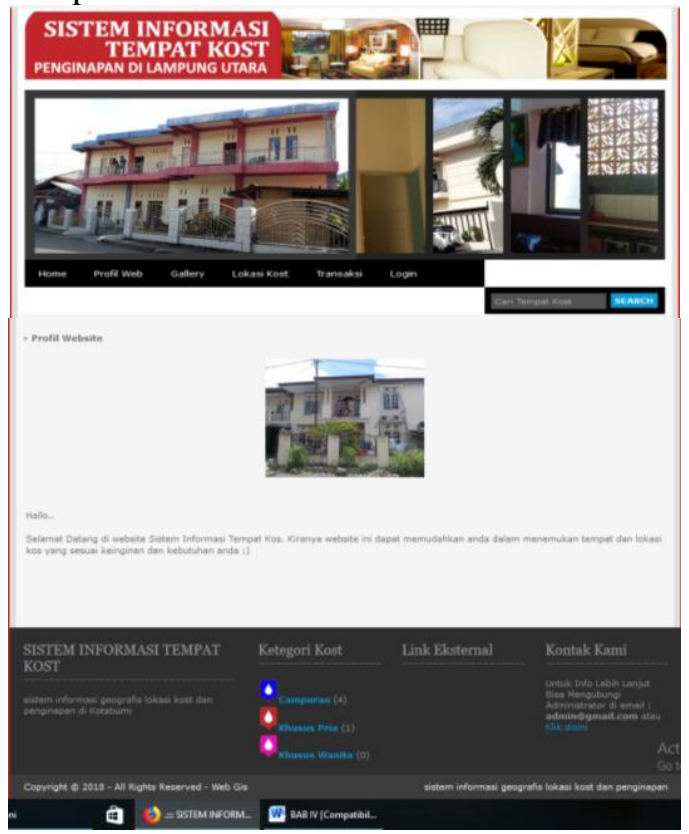

Gambar 11 Tampilan Profil Web

\subsubsection{Tampilan Galery}

Pada halaman ini user dapat melihat galery foto kosan yang tersedia diwilayah 
Lampung Utara, pemilik kosan atau penginapan akan mengupload foto fasilitas kosan dan penginapan mereka untuk menarik minat konsumen agar dapat menginap di kost ataupun penginapan mereka.

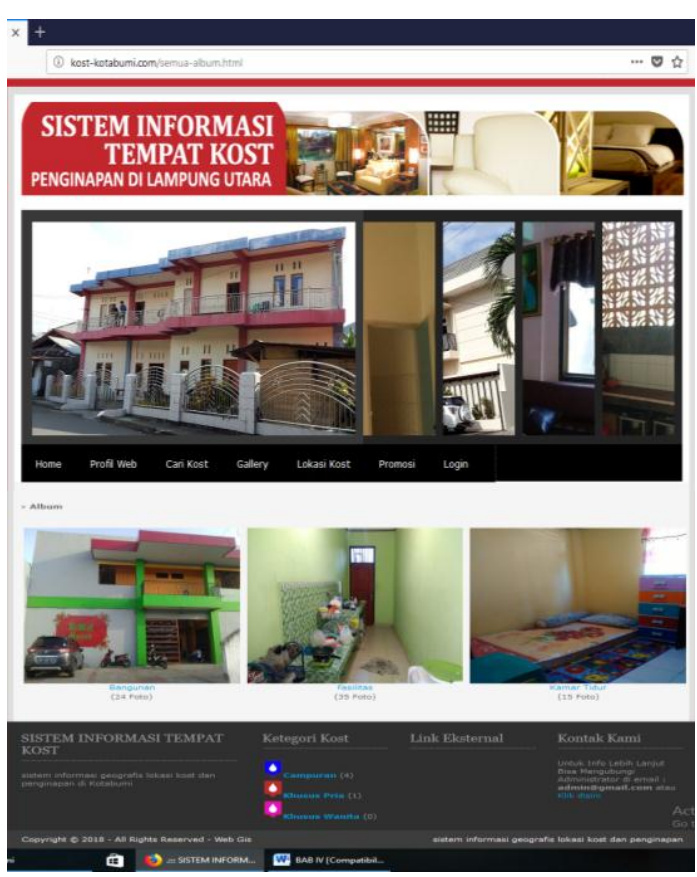

Gambar 12 Tampilan Galery

\subsubsection{Tampilan Registrasi Member}

Pada halaman ini user yang memiliki kosan dan penginapan untuk dapat login, user harus registrasi member terlebih dahulu, field - field yang diinputkan dimenu registrasi member yaitu username, password, nama, alamat, email dan no telp. Username dan password yang inputkan berguna untuk login yang kemudian member akan masuk kedalam halaman promosi kost.

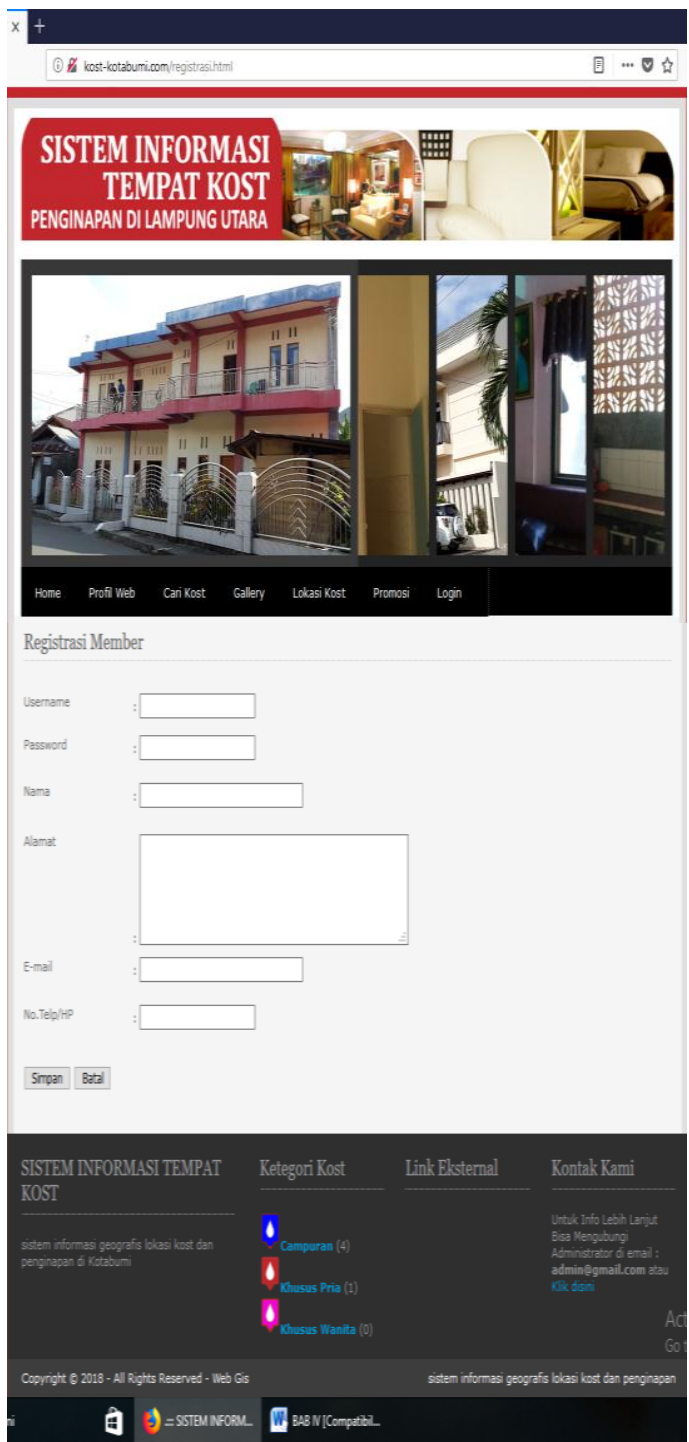

Gambar 13 Tampilan Registrasi Member

\subsubsection{Tampilan Promosi Kost}

Pada halaman ini user yang telah login, dapat mempromosikan kost dan penginapannya agar dapat ditampilkan di aplikasi. Field yang dapat user inputkan dihalaman ini yaitu nama kost, pemilik kost, harga sewa, status kamar, jumlah kamar kosong, hubungi, koordinat lokasi, alamat, kategori, keterangan dan foto. 


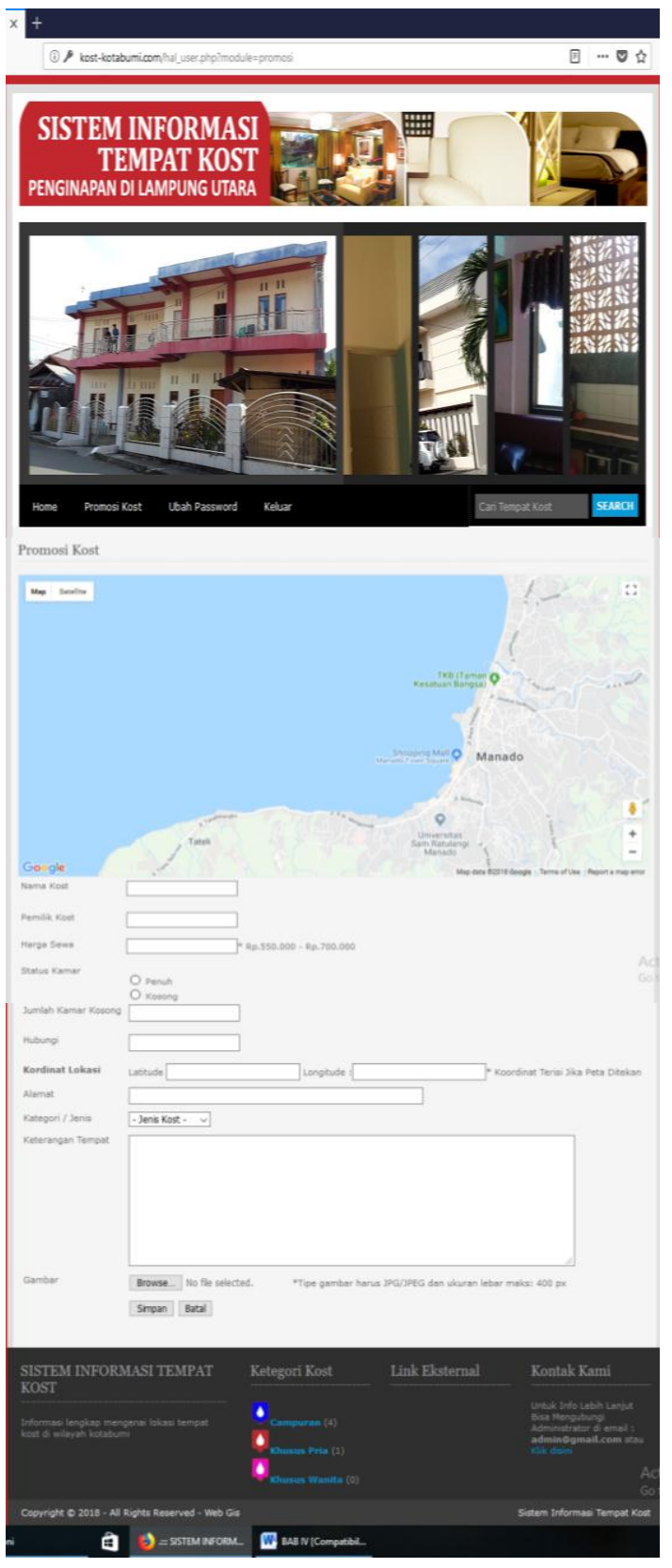

Gambar 14 Tampilan Menu Promosi Kost

\subsubsection{Tampilan Menu Penilaian Sekolah}

Pada halaman ini member dapat mengubah password mereka, untuk keamanan akun member, sebaiknya password sering diganti dalam jangka waktu tertentu.

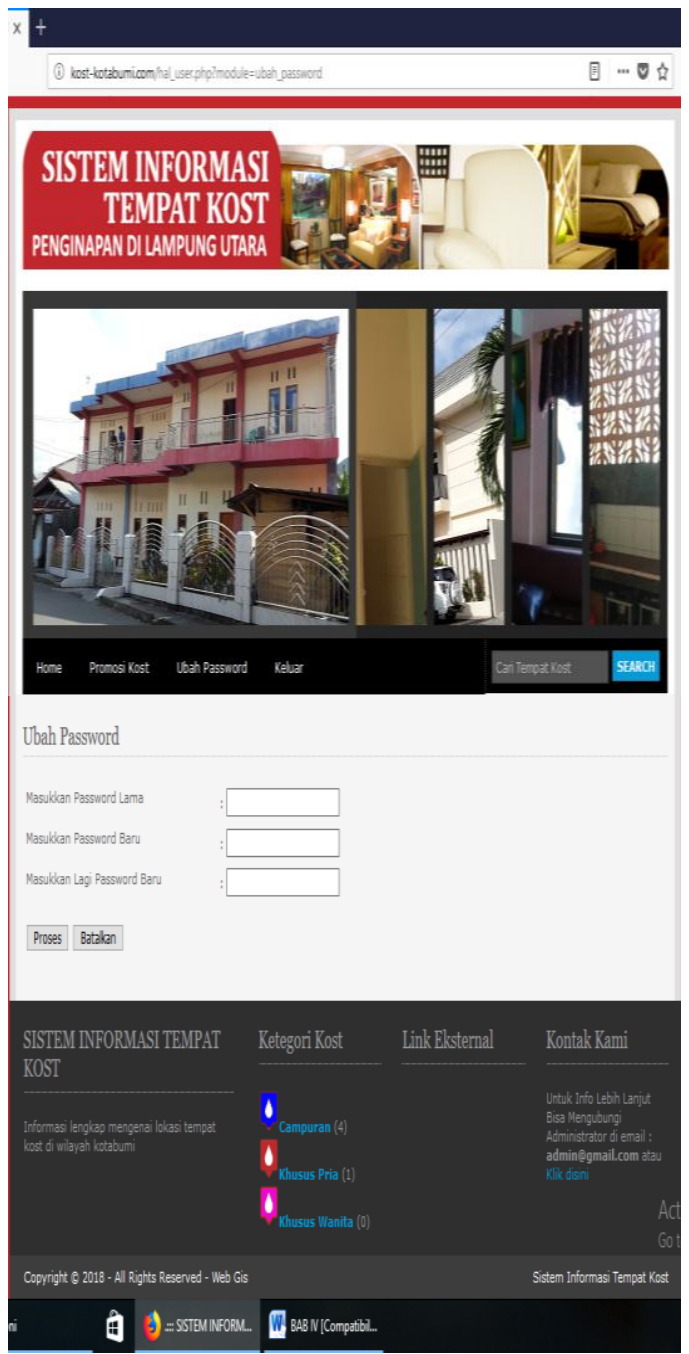

Gambar 15 Tampilan Ubah Password

\section{PENUTUP}

Berdasarkan hasil penelitian sampai pengujian sistem maka dapat diambil beberapa kesimpulan, yaitu Dengan adanya Sistem Informasi Geografis Lokasi Kost dan Penginapan di wilayah Lampung Utara ini dapat memudahkan pengguna dalam pencarian lokasi lokasi kos dan penginapan di wilayah Kotabumi Lampung Utara. 


\section{DAFTAR PUSTAKA}

[1] Mawarni, Rima. "Perencanaan Strategis Sistem Informasi Menggunakan Metode Business Systems Planning (Bsp) Pada Stmik Dian Cipta Cendikia Kotabumi." Jurnal Informasi Dan Komputer 4.1 (2016): 1-1.

[2] Mawarni, Rima. "'Sistem Informasi Penjualan Accessories Handphone Dan Pengharum Ruangan Berbasis Web Pada Toko Berkah Sukses Computindo

Pringsewu"." Jurnal Informasi Dan Komputer 6.1 (2018).

[3] Ardhy, Ferly. "Enterprise Architecture Planning (Eap) Dalam Penyusunan Perancangan Sistem Informasi Akademik Yang Terintergrasi: Studi Kasus Amik Dian Cipta Cendikia (Dcc) Bandar Lampung." Jurnal Informasi Dan Komputer 4.1 (2016).

[4] Wibowo, Koko Mukti Wibowo Mukti, Indra Kanedi, And Juju Jumadi. "Sistem Informasi Geografis (Sig) Menentukan Lokasi Pertambangan Batu Bara Di Provinsi Bengkulu Berbasis Website." Jurnal Media Infotama 11.1 (2015).

[5] Pratama, Eri Bayu. " Programming Pada Aplikasi E-Commerce Berbasis M-Commerce (Studi Kasus: Toko Buku An'nur Di Pontianak)." Jurnal Khatulistiwa Informatika 5.2 (2017). 